\title{
Purification of human anti-erythropoietin polyclonal antibodies by precipitation and chromatography as an optimized method with potential application in vaccine studies
}

\author{
Maboudi $\mathbf{K}^{1}$, Yaghoubi $\mathbf{H}^{1^{*}}$, Hadadian $\mathrm{Sh}^{2}$ \\ ${ }^{1}$ Department of Biochemistry, Ardabil Branch, Islamic Azad University, Ardabil, Iran. \\ ${ }^{2}$ Department of Research and development, Pasteur Institute of Iran, Karaj, Iran.
}

\begin{abstract}
Introduction: Polyclonal antibodies are required to be affinity purified. Improved purification methods of polyclonal antibody provide an opportunity to pick the most purified immunoglobulins as a primary or secondary antibody in immunoassays that are included in many vaccine studies. Two common techniques for purifying proteins is salt precipitation and chromatography purification. Our work focuses on purification of polyclonal antibodies against recombinant human erythropoietin (EPO) antigen using these techniques. Methods: A polyclonal antibody was produced by antigen injection with Freund's adjuvant into female albino rabbits. After separation of immunoglobulins using caprylic acid and ammonium sulfate precipitation, selected samples were analyzed by ion exchange chromatography for separation of polyclonal antibody from albumin. The purified proteins were analyzed by SDSPAGE and antibody was detected by Western Blot analysis and ELISA. Results of immunodiffusion test detected polyclonal antibody production in rabbits. Results: Caprylic acid precipitation was shown to be a more effective purification method than ammonium sulfate. Analysis of protein by spectrophotometer showed $97.6 \%$ purity by caprylic acid and $77 \%$ purity by ammonium sulfate method. Western Blot and ELISA tests confirmed the presence of antibody against EPO. Conclusion: These findings suggest that caprylic acid can be used as a quality control method in a production facility with minimal cost. On the other hand, ion exchange chromatography is the most common purification method for proteins. Therefore, combination of these techniques may effectively reduce contaminations in antibody purification procedures which may positively affect the interpretations of vaccine efficacies.
\end{abstract}

KEYWORDS: polyclonal antibodies, caprylic acid, ammonium sulfate, ion exchange chromatography, erythropoietin.

\section{INTRODUCTION}

Erythropoietin (EPO) is a growth factor for proliferation and differentiation of erythroid precursors. The EPO receptor is highly present on precursor cells; however its expression diminishes with cell maturation. EPO has known for other roles in biological functions such as in wound healing processes and in brain response to neuronal injuries [2,3]. Recombinant DNA technology in cell culture can produce exogenous EPO that has been used illicitly as a performance-enhancing drug [1,4]. The first step in producing such recombinant product is production and purification of polyclonal antibody against it [5]. In order to reduce the side effects of recombinant EPO, anti-EPO

*Corresponding Author: Hashem Yaghoubi, Department of Biochemistry, Ardabil Branch, Islamic Azad University, Ardabil, Iran.

Email: yaghoubi_h@iauardabil.ac.ir

Tel/Fax: (+98) 09125798735 / (+98) 04533727799 polyclonal antibody must be carefully produced and purified. Quality control tests should be carried out on each of the purified products according to GMP (Good Manufacturing Practice) guidelines. Moreover, the quality control tests by qualitative and quantitative evaluation techniques such as immunodiffusion, hemagglutination, Western Blot, dot blot and ELISA, determinate the presence of produced EPO and its quantity $[6,7]$.

In the field of veterinary or human medicine and immunology, purification of immunoglobulins (Ig) is required for many applications. Polyclonal antibodies are purified by three different high-performance liquid chromatography (HPLC) techniques, namely, affinity, ion exchange, and gel filtration chromatographies [8,9]. Recent works have shown that ion exchange chromatography and precipitation of antibody have a potential for rapid isolation and/or purification of polyclonal 
antibodies from biological materials. Ammonium sulfate and caprylic acid precipitation is the most commonly used method for protein purification from a solution in which water molecules are removed from the protein, leading to decrease in the protein solubility $[8,10,11]$.

Brosdky has reported that caprylic acid precipitation is an effective purification method for production facilities with minimal cost to polish chromatography techniques for monoclonal antibody purification and precipitation in cell cultures of bioreactors, prior to harvesting [11]. Bergmanleitner and Mease have selected different immunoglobulin purification methods including protein G Sepharose, polyethylene glycol and caprylic acid and ammonium sulphate precipitation to evaluate their qualitative and quantitative effects. Their results have shown that all of these techniques can purify antigen-specific antibodies of rabbit sera. Sohrabi and colleagues have also used different techniques such as ionexchange, affinity chromatography, ammonium sulfate precipitation of IgG or caprylic acid methods to purify rabbit's polyclonal antibody against recombinant coagulating factor VIII [12,13]. In this research, after polyclonal antibody production in rabbit and purification by various methods, Western blot and ELISA tests were performed to confirm the presence and the levels anti-EPO antibody.

\section{MATERIALS and METHODS}

\section{Polyclonal antibody production}

Sterile-filtered pharmaceutically active recombinant EPO was obtained from Pasteur Institute of Iran. Healthy female albino rabbits were immunized at weekly intervals by 4 subcutaneous injections, each containing approximately $200 \mu \mathrm{l}$ of recombinant EPO protein in incomplete Freund adjuvant, except for the first injection. After the last injection, followed by heart bleeding and incubation for $24 \mathrm{~h}$ and centrifuge at $10{ }^{\prime} 000 \mathrm{x} \mathrm{g}$ for $10 \mathrm{~min}$, serum was obtained and stored at $-20^{\circ} \mathrm{C}$.

Serological tests:

\section{Agglutination}

Agglutination is a sensitive method to detect a reaction between antigen and antibody. For this purpose, 2.5, 5, 10, 20, 40 and 80 $\mu 1$ of the serum was incubated on lamella. After this step, $30 \mu 1$ of antigen was added and incubated for $1 \mathrm{~min}$. The reaction was confirmed by aggregate formation.

\section{Immunodiffusion (Ouchterlony) test}

This test was performed in agar on lamella. Several holes were made on agarose gel and antigen and antibody were added to designated areas. Precipitation line of antigen and antibody reaction was observed in agar and stained for imaging. Samples were obtained in $0.15 \mathrm{M} \mathrm{NaCl}$ and precipitation lines were compared to standard solution. For staining, lamella was incubated in phosphate buffer including sodium azide for $24 \mathrm{~h}$. Buffer was then replaced three times. This step was followed by Lamella incubation in staining buffer on the shaker at $180 \mathrm{rpm}$ for $5-10 \mathrm{~min}$ at $30^{\circ} \mathrm{C}$.

\section{Antibody purification}

It should be noted that the different types of purification strategies are often used to produce a better product. In this study, ammonium sulfate, caprylic acid and ion exchange chromatography methods were used to conduct the final immunoassay.

Antibody purification by ammonium sulfate precipitation
The volume of $10 \mathrm{ml}$ of saturated ammonium sulfate was added to $20 \mathrm{ml}$ of prepared serum. This solution was mixed slowly and incubated at $4^{\circ} \mathrm{C}$ for $2 \mathrm{~h}$ to have an equilibration between the solved and the precipitated proteins. After this step, the tube was centrifuged at $1000 \mathrm{rpm}$ for $10 \mathrm{~min}$, the supernatant was discarded and the precipitate was resolved in phosphate buffer. These steps were repeated using $33.3 \%$ ammonium sulfate. The precipitated immunoglobulin was resolved in phosphate buffer with $\mathrm{pH} 7$.

Antibody purification using caprylic acid precipitation Caprylic acid is one of the three fatty acids that are found in coconut oil and used as a polyclonal antibody purification method [11]. In this step, $10 \mathrm{ml}$ serum was added to $30 \mathrm{ml}$ of 60 $\mathrm{mM}$ acetate buffer. After mixing, $\mathrm{pH}$ was adjusted to 4.5-4.8. The amount of $0.7 \mathrm{ml}$ caprylic acid was introduced dropwise under magnetic stirring condition. The solution was centrifuged at $5000 \mathrm{rpm}$ for $15 \mathrm{~min}$. Due to precipitation of most of the serum proteins with the exception of $\mathrm{IgG}$ molecules, the supernatant was dialyzed in phosphate buffer at $\mathrm{pH} 7.2$ for $16 \mathrm{~h}$. DEAE ion exchange chromatography

Ion exchange chromatography method is a widely used method for antibody purification and is applied as a second step after ammonium sulfate salt and caprylic acid precipitation [10].

In this DEAE ion exchange chromatography, $10 \mathrm{~g}$ DEAE matrix powder was mixed to $200 \mathrm{ml}$ water and incubated overnight at $4^{\circ} \mathrm{C}$. The mixture was washed 3 times and then was added to the column. The gel was incubated in 10 equal volumes of gel with $0.5 \mathrm{~N} \mathrm{HCl}$ for $30 \mathrm{~min}$. The gel was washed thoroughly by water and then by phosphate buffer until final $\mathrm{pH}$ of solution became 6.3 . The column was equilibrated with 3 column volumes of starting buffer and then sample was applied. For passing the antibody solution down the column, column attached proteins were separated by $1 \mathrm{M} \mathrm{NaCl}$. Two peaks of proteins showed that antibody ( $\mathrm{IgG})$ was eluted and presented in first peak and the other proteins located at the second peak. The purity of the proteins was analyzed by SDS-PAGE.

\section{Western bolting and ELISA}

Following proteins resolving through SDS-PAGE, the fractions were transferred to nitrocelluose membrane for detection of antibody which was then probed by its corresponding antigen/antibody reaction (i.e. our antibody product against transferred antigen). BSA 5\% was used for blocking of membrane for $30 \mathrm{~min}$. Then, the membrane was exposed to the primary and the secondary (protein A peroxidase conjugated antibody) antibodies for $2 \mathrm{~h}$. After washing of membrane by PBS, it was exposed to substrate. To confirm the presence of antibody, isolation of two chain (light and heavy chains of the antibody) was performed by 2-mercaptoethanol. Antibody binding activity was analyzed by ELISA. The concentration of the antigen was optimized and the results were read by an ELISA-plate reader at wavelength of 450 and $630 \mathrm{~nm}$.

\section{RESULTS}

\section{Serological tests}

After injection of the recombinant EPO to the rabbits, the results of agglutination, obtained from reaction of the purified produced antibody and the antigen showed that the titer of polyclonal antibody in which the agglutination reaction was obtained was within the lowest and the highest limits of detection (i.e. $1 / 20$ and $1 / 320$ dilutions, respectively). Meanwhile, no agglutination was observed in the control tubes with different titers of the antigen before the injection. The 
objective of immunodiffusion test was to provide a quantitative estimate of the antibody using the precipitation line of the antigen-antibody reaction. The results of this test indicated that the antibody was produced and diffused in required quantities.

\section{Purification by precipitation and chromatography}

The purity of the antibody purification by ammonium sulfate precipitation was calculated using this formula:

$\mathrm{OD}$ of $\mathrm{Ab} \times 13.6=$ Concentration of $\mathrm{Ab}(\mathrm{mg} / \mathrm{ml})$.

$\mathrm{OD}=0.89$ in $280 \mathrm{~nm}$

$0.89 \times 13.6=12.1 \mathrm{mg} / \mathrm{ml}$

Antibody preparations and purity degree was shown by DEAE ion exchange chromatography as $77 \%$.

Purification using caprylic acid precipitation analyzed by spectrophotometer showed OD $=1.09$ in $280 \mathrm{~nm}$, so concentration of Ab was $1.09 \times 13.6=14.82 \mathrm{mg} / \mathrm{ml}$. Depending on the necessary antibody purity, DEAE chromatography was coupled with a further purification step which resulted in a high purity of $97 \%$.

\section{Detection tests}

In the course of antibody purification, the easiest way to confirm the purity of an antibody is Western blotting. The fractions of SDS-PAGE were transferred to nitrocellulose membrane and detected by the enzyme activity. The Western Blot result of antibody chains on nitrocellulose is shown in Fig. 1. The output included antibody digestion results, the light and heavy chains of the antibody with 30 and $60 \mathrm{kDa} \mathrm{Mw}$ are depicted in Fig. 2.

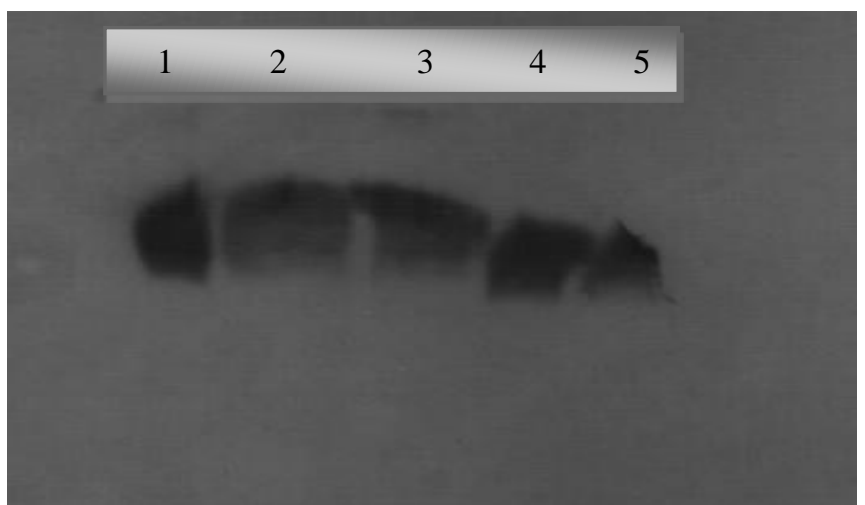

Fig. 1. Western Blotting result. Lane 1: marker (standard erythropoietin). Lane 2-5: purified antibodies.

1

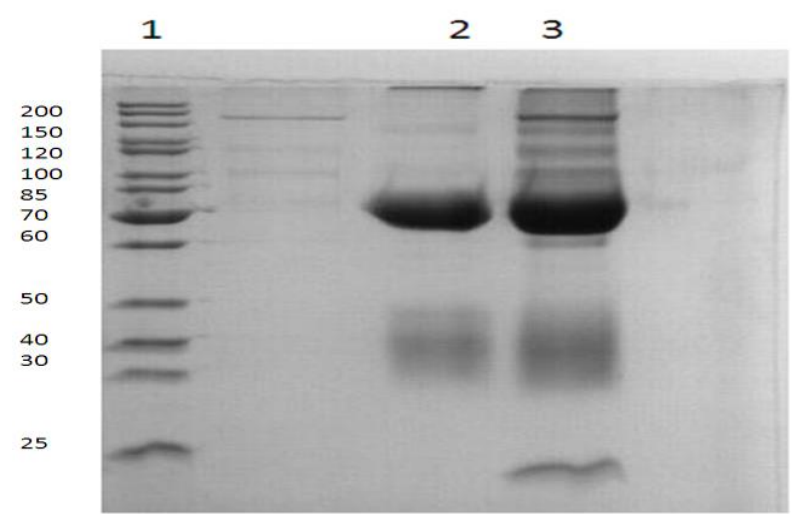

Fig. 2. Results of antibody digestion. Lane1: marker $25 \mathrm{kDa}$. Lane 2: Antibody after purification by DAEA-cellulose column. Lane 3: Antibody before purification by DAEA- cellulose column.

ELISA test analyzed the antigen binding capacity of the antibodies. The results observed in Fig. 3 show that the optimum dilution of purified coating antibody was 1/100 according to the conjugated antibody.

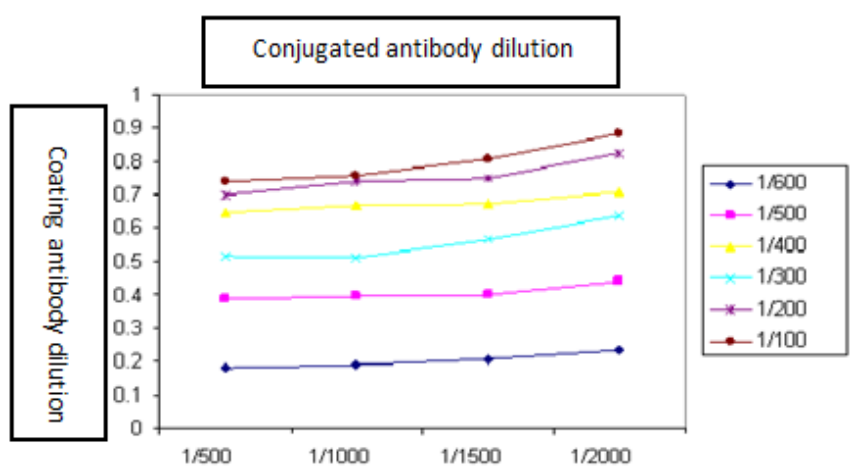

Fig. 3. ELISA results show that the $1 / 100$ dilution of purified antibody had the most absorbance in ELISA reader.

\section{DISCUSSION}

The requirement for the quality control of biological products such as pharmaceutical material include toxicity testing, freedom from contaminants and antibiotics, biological and immunological stability and potency. A critical part of quality control is about the identity and the full characterization of the host cells. For these reasons, manufacturers refer to Guide for Good Manufacturing Practice for Medicinal Products. This reference contains measures to ensure the quality, immunological and biological activity, present and safety of the final product like use of poly and monoclonal antibodies, isoenzyme and immunological materials $(7,9)$. There are several commercial polyclonal antibody purification strategies available. For instance, ammonium sulfate and caprylic acid precipitation, hydroxylapatitechromatography, DEAE ion exchange chromatography and immunoaffinity chromatography, to name a few. The produced antibody is dependent on employing techniques like Western blotting and ELISA [10-12].

Recombinant human EPO hormone that has been started to be marketed and used in medical care is purified by several methods that require antibody. Stec and Bicka have worked on purified polyclonal IgG antibodies from bovine serum. Their methods were based on combination of affinity, ion-exchange and gel filtration chromatography. Their results of high performance adsorption chromatography technique have confirmed the percent of purity of the chromatographic fractions. The purities obtained by ammonium sulfate precipitation and gel filtration chromatography were found to be approximately $75 \%$ [8].

Eivazi and colleagues have produced and purified a polyclonal antibody against purified mouse IgG2b in Rabbits. In their study, ion-exchange chromatography and affinity chromatography were considered appropriate and recommended techniques for purification of mouse $\mathrm{IgG}$ and IgG subclasses. Their purified antibody was obtained and precipitated at $50 \%$ ammonium sulfate concentration. The percent of purity of their rabbit anti-mouse $\operatorname{IgG} 2 \mathrm{~b}$ was approximately 95\% [5]. Bergmann-Leitner and Mease have used various immunoglobulin purification methods including SDS-PAGE to evaluate the biological activity of purified rabbit and human antibodies. Their results have demonstrated that overall polyethylene glycol purification of human serum 
samples and gel filtration purification of rabbit sera are best methods for recovering functional antibodies [6].

EPO is used as a recombinant drug for several diseases and has a complicated purification procedure. Polyclonal antibodies are used as a selective and sensitive tool to shorten this complicated procedure. In this study, the caprylic acid and ammonium sulfate method were coupled with DEAE ion exchange chromatography. Our results indicated $77 \%$ purity obtained by ammonium sulfate and $97 \%$ by caprylic acid methods.Therefore, critical consideration of the purification is required to avoid selecting non-representative populations of antibodies in such a complicated process which could be a major factor in many biological investigations such as determination of vaccine efficacies.

\section{ACKNOWLEDGEMENT}

The authors are grateful to the biology department at azad university of Ardabil.

\section{CONFLICT OF INTEREST}

The authors declare that they have no conflict of interest.

\section{REFERENCES}

1. Ng T, Marx G, Littlewood T, Macdougall I. Recombinant erythropoietin in clinical practice. Postgrad Med J. 2003;79(933):367-76.

2. Haroon ZA, Amin K, Jiang X, Arcasoy MO. A novel role for erythropoietin during fibrin-induced wound-healing response. Am J Pathol. 2003;163(3):993-1000. doi:10.1016/S0002-9440(10)63459-1.

3. Siren AL, Fratelli M, Brines M, Goemans C, Casagrande S, Lewczuk P et al. Erythropoietin prevents neuronal apoptosis after cerebral ischemia and metabolic stress. Proc Natl Acad Sci U S A. 2001;98(7):4044-9. doi:10.1073/pnas.051606598.
4. van Iperen CE, Gaillard CA, Kraaijenhagen RJ, Braam BG, Marx JJ, van de Wiel A. Response of erythropoiesis and iron metabolism to recombinant human erythropoietin in intensive care unit patients. Crit Care Med. 2000;28(8):2773-8

5. Eivazi S, Majidi J, Aghebati Maleki L, Abdolalizadeh J, Yousefi M, Ahmadi $\mathrm{M}$ et al. Production and Purification of a Polyclonal Antibody Against Purified Mouse IgG2b in Rabbits Towards Designing Mouse Monoclonal Isotyping Kits. Adv Pharm Bull. 2015;5(1):109-13. doi:10.5681/apb.2015.015.

6. Bergmann-Leitner ES, Mease RM, Duncan EH, Khan F, Waitumbi J, Angov E. Evaluation of immunoglobulin purification methods and their impact on quality and yield of antigen-specific antibodies. Malar J. 2008;7:129. doi:10.1186/1475-2875-7-129.

7. Nebija D, Noe CR, Urban E, Lachmann B. Quality control and stability studies with the monoclonal antibody, trastuzumab: application of 1D- vs 2D-gel electrophoresis. Int J Mol Sci. 2014;15(4):6399-411. doi:10.3390/ijms15046399.

8. Stec J, Bicka L, Kuzmak J. Isolation and purification of polyclonal IgG antibodies from bovine serum by high performance liquid chromatography. BULLETIN-VETERINARY INSTITUTE IN PULAWY. 2004;48(3):321-8. 9. Verdoliva A, Basile G, Fassina G. Affinity purification of immunoglobulins from chicken egg yolk using a new synthetic ligand. J Chromatogr B Biomed Sci Appl. 2000;749(2):233-42.

10. Tishchenko GA, Bleha M, Skvor J, Bostik T. Effect of salt concentration gradient on separation of different types of specific immunoglobulins by ion-exchange chromatography on DEAE cellulose. J Chromatogr B Biomed Sci Appl. 1998;706(1):157-66.

11. Brodsky Y, Zhang C, Yigzaw Y, Vedantham G. Caprylic acid precipitation method for impurity reduction: an alternative to conventional chromatography for monoclonal antibody purification. Biotechnol Bioeng. 2012;109(10):2589-98. doi:10.1002/bit.24539.

12. Sohrabi S, Akbarzadeh A, Norouzian D, Farhangi A, Mortazavi M, Mehrabi MR et al. Production and Purification of Rabbit's Polyclonal Antibody Against Factor VIII. Indian Journal of Clinical Biochemistry. 2011;26(4):354-9.

13. Cheung HY, Chan KM, Ng TB, Cheng CH. Production of a polyclonal antibody against recombinant goldfish prolactin and demonstration of its usefulness in a non-competitive antigen-capture ELISA. Comp Biochem Physiol B Biochem Mol Biol. 2002;131(1):37-46. 